\title{
Caracterização do gene do choque térmico (HSP-70.1) e sua relação com características de produção em bovinos leiteiros criados no semiárido brasileiro
}

[Characterization of the thermal shock gene (HSP-70.1) and its relationship with production characteristics in dairy cattle reared in the Brazilian semiarid]

\author{
M.D.S. Araújo ${ }^{1}$, E.P.M. Luna ${ }^{1}$, J.C.V. Oliveira ${ }^{2}$, S.I. Guido ${ }^{2}$, E.C. Silva ${ }^{3}$, \\ S.B.P. Barbosa ${ }^{3}$, K.R. Santoro ${ }^{1}$ \\ ${ }^{1}$ Programa de pós-graduação - Unidade Acadêmica de Garanhuns - UFRPE - Garanhuns, PE \\ ${ }^{2}$ Instituto Agronômico de Pernambuco - Recife, PE \\ ${ }^{3}$ Universidade Federal Rural de Pernambuco - Recife, PE
}

\begin{abstract}
RESUMO
Objetivou-se com este trabalho avaliar a diversidade genética do gene HSP-70.1 e associar os polimorfismos encontrados com a performance de vacas leiteiras das raças Holandesa, Girolando $(5 / 8 \mathrm{H}-$ G) e Sindi criadas em região do semiárido brasileiro. Os polimorfismos foram identificados e avaliados pela técnica de PCR-RFLP, usando-se a enzima de restrição EcoRII. Avaliou-se a variabilidade genética por meio do índice de diversidade padrão e da análise de variância molecular (AMOVA). Os polimorfismos identificados foram avaliados sobre as características de produção de leite. Foram identificados sete alelos, os quais demonstraram que houve polimorfismo para a região gênica analisada, e alguns alelos foram compartilhados entre os rebanhos. As raças bovinas Holandesa e Sindi foram similares geneticamente para o gene analisado. A AMOVA demonstrou que há variação genética entre os rebanhos e dentro deles, com a maior parte da variação ocorrendo dentro dos rebanhos para todos os grupos avaliados. Houve efeito dos alelos identificados sobre a produção de leite dos rebanhos das raças Holandesa $(\mathrm{P}<0,0001)$ e Girolando ( $\mathrm{P}<0,0117)$. O gene HSP-70.1 foi polimórfico na população de bovinos leiteiros estudada, sendo, portanto, um marcador molecular promissor para avaliar a produção de leite de raças criadas em região semiárida.
\end{abstract}

Palavras-chave: bovinos leiteiros, estresse por calor, EcoRII, PCR-RFLP

\begin{abstract}
The objective of this work was to evaluate the genetic diversity of the HSP-70.1 gene and to associate the polymorphisms found with the performance of Holstein, Girolando $(5 / 8 H-G)$ and Sindi dairy cows raised in region of the Brazilian semiarid. Polymorphisms were identified and evaluated using the PCR-RFLP technique using the EcoRII restriction enzyme. Genetic variability was evaluated using the standard diversity index and molecular variance analysis (AMOVA). The identified polymorphisms were evaluated on the characteristics of milk production. They were identified from the seven alleles, demonstrating that there was polymorphism for the analyzed gene region and some alleles were shared among the herds. The Holstein and Sindi bovine breeds were genetically like the analyzed gene. AMOVA demonstrated that there is genetic variation between and within the herds, with most of the variation occurring within the herds for all groups evaluated. There was effect of the alleles identified on the production of milk herds of Holstein and $(P<0.0001)$ Girolando $(P<0.0117)$ breeds. The HSP-70.1 gene was polymorphic in the population of dairy cattle studied, and therefore a promising molecular marker to evaluate milk production of breeds created in semiarid regions.
\end{abstract}

Keywords: Dairy cattle; Heat stress; EcoRII; PCR-RFLP

Recebido em 30 de novembro de 2018

Aceito em 20 de novembro de 2019

E-mail: maria.araujo_zoo@hotmail.com 


\section{INTRODUÇÃO}

No Brasil, a atividade leiteira tem se destacado no setor agropecuário, apesar de os fatores climáticos dificultarem a produção de leite, em algumas regiões do país, uma vez que ocasionam a diminuição da imunidade e dos desempenhos produtivo e reprodutivo dos animais (Berman, 2011). O estresse calórico é considerado o principal responsável pela redução da produtividade animal em regiões tropicais e gera graves consequências econômicas para a agropecuária global (Bernabucci et al., 2010).

Na região Nordeste do Brasil, encontra-se a maior área semiárida nacional, sendo um entrave para a bovinocultura de leite praticada na região devido aos longos períodos de estiagens aliados às elevadas temperaturas, que resultam em carga total de calor superior à capacidade de dissipação dos animais e gera respostas fisiológicas, comportamentais e celulares que comprometem a produção (Delfino et al., 2012) e a reprodução de vacas leiteiras (Lima et al., 2013).

Estudos demonstram diferenças adaptativas entre zebuínos e taurinos quando se trata de estresse calórico (Hansen, 2004; Camargo et al., 2007). Apesar de terem surgido de um ancestral comum, essas duas subespécies foram submetidas a diferentes condições ambientais, que levaram a distintos graus de evolução, entre os quais a seleção por genes que protegem as células de animais submetidos à temperatura elevada (Bradley et al., 1996).

As proteínas de choque térmico (Heat Shock Protein 70-HSP-70) fazem parte de uma grande família das HSPs e funcionam como chaperonas moleculares, as quais modulam a resposta ao estresse térmico e minimizam lesões celulares (Castro et al., 2013). Essas proteínas têm sido indicadas como principais responsáveis pela termotolerância, destacando-se as HSPs-70 (HSP70.1 e HSP-70.2) pela sua abundância e sensibilidade à temperatura (Maróti-Agóts et al., 2011). Nos bovinos, os genes que codificam as HSP-70.1 estão localizados no cromossomo 23 (BTA 23), nas imediações do complexo principal de histocompatibilidade (MHC) (Grosz et al., 1992). A caracterização desse gene já foi realizada para algumas espécies de animais de interesse zootécnico, como suínos (Nunes et al., 1993), caprinos (Gade et al., 2010), bubalinos (Manjari et al., 2015)) e bovinos (Grosz et al., 1992).

A HSP-70.1 tem ação de proteção celular pela maior termotolerância e habilidade em apoiar a sobrevivência da célula ao estresse térmico (Castro et al., 2013; Maróti-Agóts et al., 2011). A identificação de polimorfismos desse gene possibilita, além da melhoria na resistência térmica, melhoria no desempenho zootécnico dos animais que são comprometidos pelo estresse térmico (Adamowig et al., 2005).

Diante da importância do gene em conferir melhores condições de termotolerância, objetivou-se identificar polimorfismos no gene HSP-70.1 e avaliar se os polimorfismos identificados estão associados com a produção de leite de bovinos leiteiros criados em região semiárida do estado de Pernambuco, Brasil.

\section{MATERIAL E MÉTODOS}

Todos os procedimentos utilizados no presente estudo foram aprovados pela Comissão de Ética no Uso de Animais da Universidade Federal Rural de Pernambuco (Ceua/UFRPE), com processo $n^{\circ}$ 23082.004484/ 2009.

Para realização deste trabalho, foram utilizadas amostras de DNA genômico de 213 vacas, sendo 65 da raça Holandesa, 106 da raça Girolando (5/8 $\mathrm{H}-\mathrm{G})$ e 42 da raça Sindi. Esses animais foram provenientes do estado de Pernambuco, das Estações Experimentais do Instituto Agronômico de Pernambuco-IPA, dos municípios de São Bento do Una e Arcoverde, e da Empresa Brasileira de Pesquisa Agropecuária - Embrapa, localizada no município de Petrolina. Para a extração de DNA, foram coletados, de cada animal, 4,5mL de sangue, por meio de punção venosa da jugular, em tubos Vacutainer com anticoagulante (EDTA).

A extração de DNA foi realizada com o kit de extração Axy PrepTM Blood Genomic DNA Miniprep $\mathrm{Kit}^{\circledR}$ (Axygen), segundo as recomendações do fabricante. A qualidade do material extraído foi avaliada em gel de agarose a $1 \%$, o qual foi corado com SYBR GREEN ${ }^{\circledR}$ (Invitrogen), visualizado em luz ultravioleta $\mathrm{e}$ fotodocumentado (Gel Logic 112 ${ }^{\circledR}$, Kodak). 
A técnica de PCR-RFLP (Polimerase Chain Reaction - Restriction Fragment Length Polymorphism) foi utilizada para a obtenção dos polimorfismos. Para a amplificação do gene HSP70, por meio da técnica de reação em cadeia da polimerase (PCR), utilizou-se um par de primer descrito por Schwerin et al. (2003): 5'GTCGCCAGGAAACCAGAGAC-3' e 5'GGAACACCCCTACGCAGGAG -3'. Cada reação de amplificação de $50 \mu \mathrm{L}$ foi constituída por $5 \mu \mathrm{L}$ de tampão $1 \mathrm{X}, 5 \mathrm{mM}$ de $\mathrm{MgCl} 2,0,4 \mathrm{mM}$ de dNTP, 0,2 unidade de Taq DNA polimerase (Invitrogen) e 100ng de DNA, sendo conduzida em termociclador (Mastercycler ${ }^{\circledR}$ Pro, Eppendorf, Germany) programado para um ciclo de $94^{\circ} \mathrm{C}$ por cinco minutos, 40 ciclos de $94^{\circ} \mathrm{C}$ por um minuto, $63^{\circ} \mathrm{C}$ por um minuto, $72^{\circ} \mathrm{C}$ por dois minutos e um ciclo de extensão final de $72^{\circ} \mathrm{C}$ por cinco minutos. O produto da amplificação foi analisado em gel de agarose a $2 \%$.

Em seguida, os amplicons gerados foram submetidos à digestão com a enzima de restrição EcoRII (Invitrogen). Para cada reação de digestão enzimática, foram utilizados $12 \mu \mathrm{L}$ do produto de PCR, $15 \mu \mathrm{L}$ de $\mathrm{H}_{2} \mathrm{O}$ deionizada autoclavada, $2 \mu \mathrm{L}$ de tampão e $1 \mu \mathrm{L}$ da enzima de restrição, totalizando $30 \mu \mathrm{L}$. A digestão enzimática foi realizada em termociclador programado para um ciclo de $37^{\circ} \mathrm{C}$ por cinco horas. Os polimorfismos foram identificados pelo padrão de fragmentos observados em gel de poliacrilamida a $8 \%$.

Com base nos polimorfismos identificados, foram realizadas análises para se determinar a variabilidade genética pela frequência gênica e pelo índice de diversidade padrão nos rebanhos. A avaliação da estrutura genética populacional entre os rebanhos e dentro deles foi realizada pela análise de variância molecular (AMOVA), por meio do software Arlequim, versão 3.5.1.2. (Excoffier e Lischer, 2010).

Para a construção das árvores filogenéticas, utilizou-se o coeficiente de Jaccard (1908), pelo método de agrupamento UPGMA (Unweighted Pair Group Method using Arithmetic averages), por meio do software SAS. O estudo de associação foi realizado entre os polimorfismos identificados e a produção de leite de 131 animais, sendo 52 da raça Holandesa e 79 da raça
Girolando (5/8 H-G). Além dos dados de produção de leite, foram obtidas as médias climáticas de precipitação, temperatura e umidade nas cidades de São Bento do Una (A) e Arcoverde (B), entre os anos de 2006 e 2014 (Fig. 3), gerando 3.019 observações. Os dados das variáveis analisadas foram submetidos à análise de variância e ao teste $\mathrm{t}$ a $5 \%$ de probabilidade, pelo procedimento GLM do SAS 9.3, por meio do modelo estatístico:

$$
\begin{gathered}
\mathrm{yijk}=\mu+\mathrm{Pj}+\mathrm{Ak}+\mathrm{Ml}+\mathrm{Ak} * \mathrm{Ml}+\mathrm{Ti}+\mathrm{Ui}+\mathrm{Pi} \\
+\varepsilon \mathrm{ij},
\end{gathered}
$$

em que: yijk é a i-ésima produção de leite (litros) por dia, $\mu$ é uma constante comum a todas as observações, $\mathrm{Pj}$ é o efeito do j-ésimo polimorfismo genético, Ak é o efeito do k-ésimo ano, Ml é o efeito do l-ésimo mês, Ak*Ml é a interação do k-ésimo ano com o l-ésimo mês, Ti é a temperatura média diária $\left({ }^{\circ} \mathrm{C}\right)$, Ui é a umidade relativa média diária (\%), Pi é a pluviosidade total diária $(\mathrm{mm})$, cij é o erro aleatório associado às observações.

\section{RESULTADOS E DISCUSSÃO}

A digestão do produto da PCR gerou 17 diferentes fragmentos, que caracterizaram sete padrões de alelos: A; B; C; D; E; F; G na população analisada. Entre os padrões de alelos apresentados, apenas três (B, D e E) foram compartilhados entre os rebanhos, com frequências de: $22,44 \%, 8,97 \%$ e $51,92 \%$, respectivamente. Os alelos $\mathrm{A}, \mathrm{F}$ e $\mathrm{G}$ não foram compartilhados, enquanto $\mathrm{o}$ alelo $\mathrm{C}$ foi compartilhado entre os rebanhos das raças Holandesa e Sindi.

Os padrões alélicos identificados na amostra estudada foram utilizados para construção da árvore filogenética e resultaram na formação de cinco grupos principais (clusters), com a distância máxima observada entre os padrões de 1,2908 (Fig. 1). A árvore filogenética com a distância entre as raças (Fig. 2) demonstra a presença de três diferentes grupos (clusters), sendo a distância máxima observada de 1,1371. Apesar das diferenças genéticas observadas, a raça Holandesa foi mais semelhante à raça Girolando, demonstrando a participação da composição genética da raça Holandesa na formação do gado Girolando. 


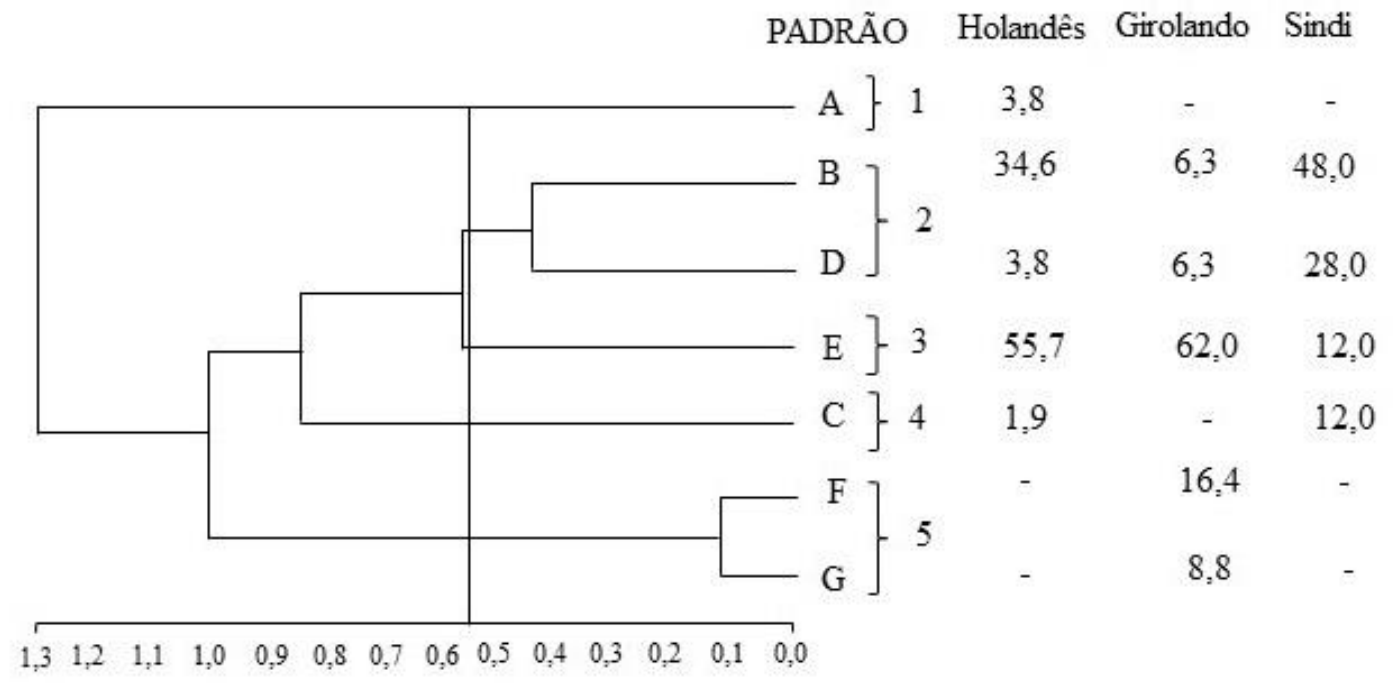

Figura 1. Dendrograma dos padrões PCR-RFLP e respectivas frequências (\%) encontradas para o gene HSP-70.1, em rebanhos leiteiros Holandesa, Girolando (5/8 H-G) e Sindi, no estado de Pernambuco. Os números de 1 a 5 representam os cinco clusters formados.

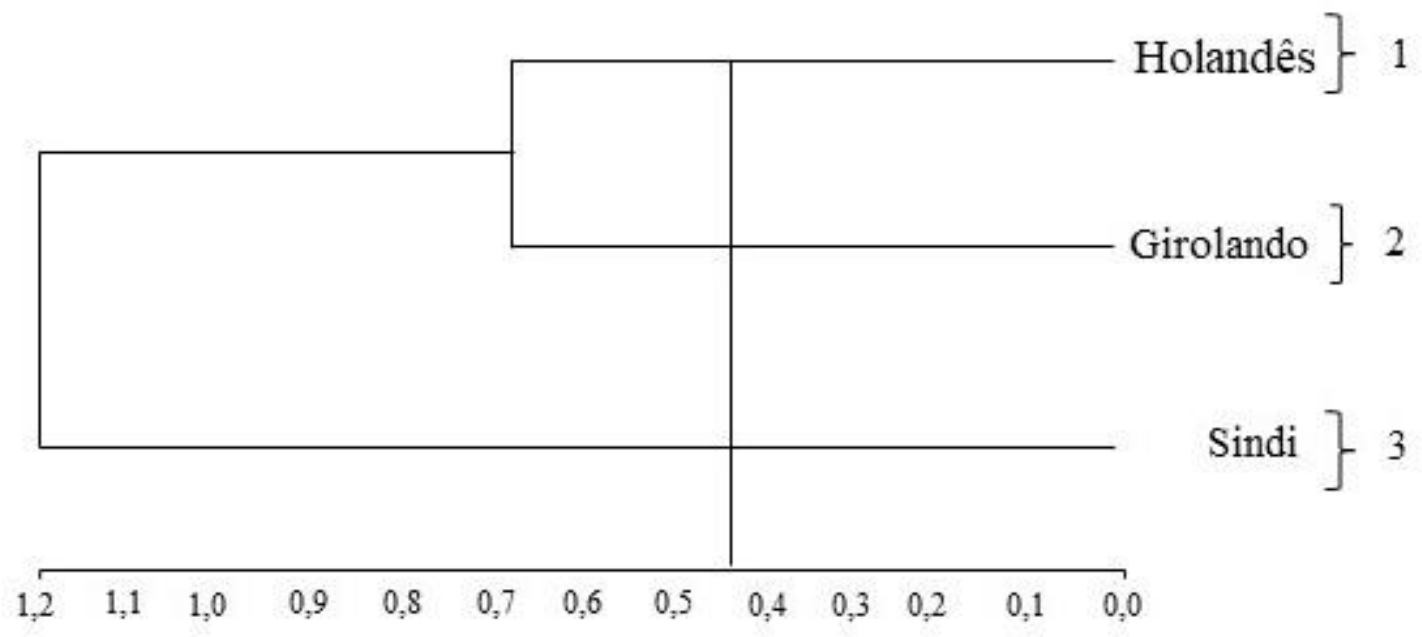

Figura 2. Dendrograma com a distância entre as três raças analisadas (Holandesa, Girolando (5/8 H-G) e Sindi) no estado de Pernambuco. Os números de 1 a 3 representam os clusters com separação das três raças de bovinos leiteiros analisadas.

O conhecimento da variabilidade genética entre populações aparece como peça fundamental para o melhoramento genético; com base nele, é possível tomar medidas adaptativas diante das mudanças ocasionadas pelo desenvolvimento dos sistemas de produção. Apesar de surgirem de um ancestral comum, o gado europeu (Bos taurus) e o gado indiano (Bos indicus) submeteram-se a processos de evolução separados em razão das migrações pré-históricas, as quais contribuíram para a formação das muitas raças observadas atualmente, que divergem geneticamente devido às adaptações sofridas ao longo do tempo (Bradley et al., 1996). Entretanto, a maior semelhança gênica observada neste estudo, entre os padrões dos rebanhos Holandês e Sindi, não era esperada, visto que maiores semelhanças deveriam ocorrer entre os rebanhos Holandês e Girolando ou entre a raças Sindi e Girolando, em 
razão da participação das raças na formação da raça Girolando.

O índice de diversidade padrão revelou maior diversidade entre os animais do rebanho Sindi quando comparados aos demais (Tab. 1). Verificou-se que a diversidade entre os rebanhos foi menor que a diversidade dentro do rebanho. Essa diversidade pode ser justificada pelo manejo reprodutivo adotado nas estações experimentais, que utiliza a inseminação artificial, uma vez que o uso de sêmen de diversos touros disponíveis no mercado diminui a endogamia e a fixação de alelos.

Tabela 1. Índice de diversidade padrão para o gene HSP-70.1 em rebanhos leiteiros das raças Holandesa, Girolando (5/8 H-G) e Sindi, no estado de Pernambuco

\begin{tabular}{cc} 
Raças & Índice de diversidade padrão \\
\hline Holandesa & $0,5769 \pm 0,0468$ \\
Girolando & $0,5797 \pm 0,0561$ \\
Sindi & $0,6900 \pm 0,0642$ \\
\hline
\end{tabular}

O gene HSP-70.1 apresenta papel vital na resposta ao estresse térmico, e o conhecimento da variabilidade genética deste vem a contribuir grandemente para a bovinocultura de leite do estado de abrangência do estudo, o que possibilita a exploração das diferentes respostas apresentadas pelos animais em condições de estresse por calor. $\mathrm{O}$ estresse térmico em bovinos leiteiros deve ser minimizado para que os animais se mantenham saudáveis, a produção se aperfeiçoe e, consequentemente, as perdas econômicas se reduzam (Wolfenson et al., 2000).
A análise de variância molecular (AMOVA) demonstrou grande variação genética entre os rebanhos e dentro deles, com a maior parte da variação ocorrendo dentro dos rebanhos para todos os grupos avaliados (Tab. 2). Esse fato foi confirmado pelo índice de diferenciação genética $\left(\mathrm{F}_{\mathrm{ST}}\right)$, que apresentou de níveis moderados a muito altos de diferenciação quando se compararam as frequências dos alelos nos rebanhos.

Tabela 2. Análise de variância molecular (AMOVA) para as raças Holandesa, Girolando (5/8 H-G) e Sindi para o gene HSP-70.1

\begin{tabular}{ccccc}
\hline Raças & F.V. & C.V. & $\% \mathrm{~V}$. & $\mathrm{F}_{\mathrm{ST}} * *$ \\
\hline $\begin{array}{c}\text { Holandesa } \\
\text { Girolando } \\
\text { Sindi }\end{array}$ & Entre rebanhos & $0,46350 \mathrm{Va}$ & 18,41 & \multirow{2}{*}{0,18413} \\
\hline $\begin{array}{c}\text { Holandesa } \\
\text { Girolando }\end{array}$ & Dentro dos rebanhos & $2,05368 \mathrm{Vb}$ & 81,59 & \\
\hline $\begin{array}{c}\text { Holandesa } \\
\text { Sindi }\end{array}$ & Entre rebanhos & $0,32149 \mathrm{Va}$ & 12,86 & \multirow{2}{*}{0,12857} \\
\hline $\begin{array}{c}\text { Girolando } \\
\text { Sindi }\end{array}$ & Entre rebanhos & $0,30850 \mathrm{Va}$ & 16,87 & \multirow{2}{*}{0,16874} \\
\hline
\end{tabular}

F.V.: fonte de variação; C.V.: componentes de variância; \%V.: percentual de variação.

** Significativo a $1 \%(\mathrm{P}<0,01)$ para todas as comparações.

As estatísticas descritivas para produção de leite estão sumarizadas na Tab. 3, e para os dados climáticos na Fig. 3. A análise de variância demonstrou a significância dos efeitos sobre a variável produção de leite (Tab. 4), e foram observadas diferenças de produção em razão dos padrões para ambos os rebanhos (Tab. 5). 
Tabela 3. Estatísticas descritivas da produção de leite (L/dia) dos rebanhos bovinos Holandês e Girolando, de acordo com cada padrão alélico identificado como gene HSP-70.1

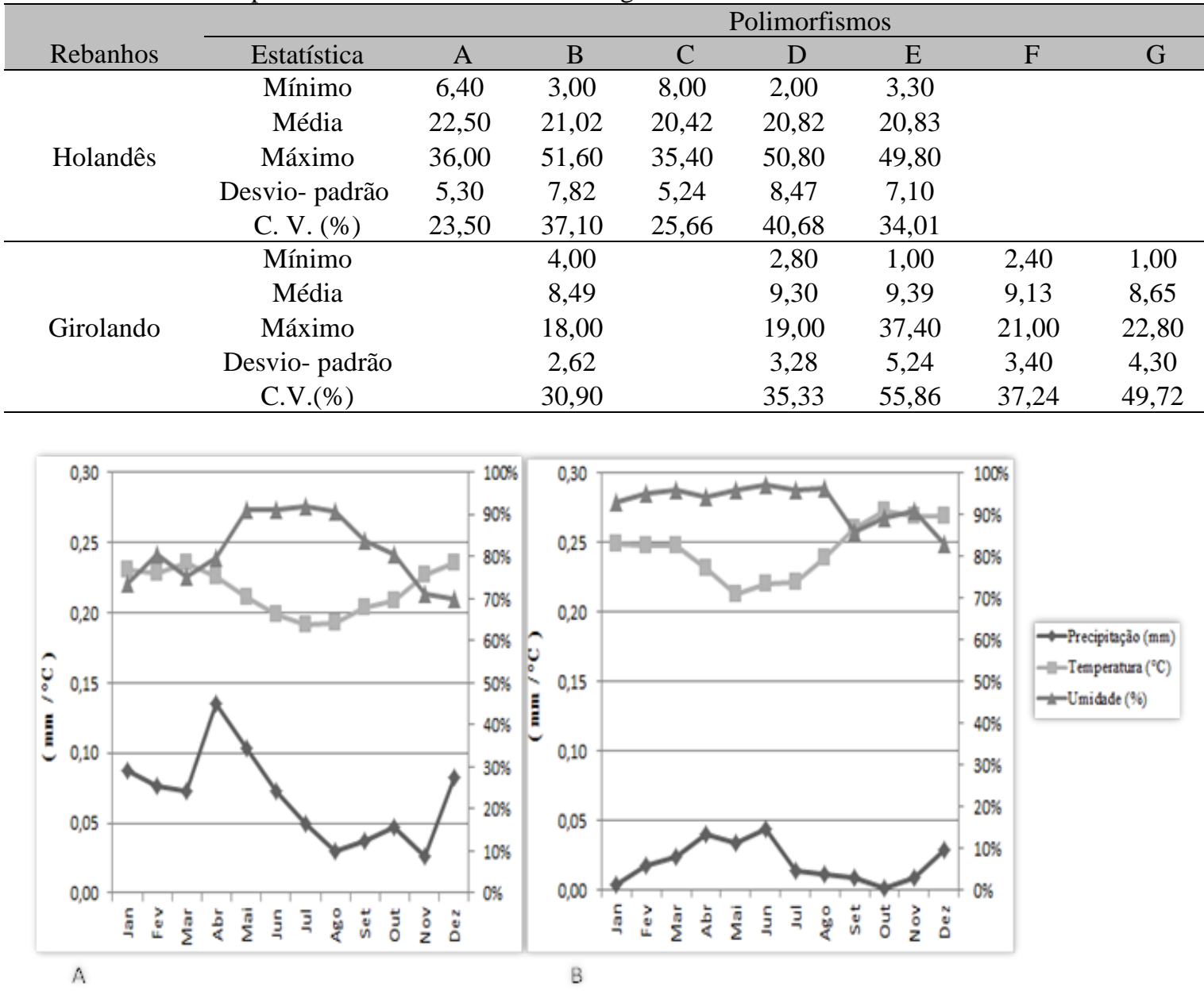

Figura 3. Médias climáticas de precipitação $(\mathrm{mm})$, temperatura $\left({ }^{\circ} \mathrm{C}\right)$ e umidade relativa $(\%)$ nas cidades de São Bento do Una (A) e Arcoverde (B), entre os anos de 2006 e 2014.

As maiores médias de produção foram observadas nos rebanhos Holandês e Girolando que apresentaram os padrões alélicos A e E (Tab. 3), entretanto grandes diferenças foram observadas entre as médias dos rebanhos, o que pode ser justificado pelas diferenças raciais, visto que a raça Holandesa é especializada em produção de leite (Zanela et al., 2006), assim como pelas condições climáticas apresentadas pelos locais onde os animais foram criados.

Para obter-se incremento de produtividade em regiões que apresentam temperaturas elevadas, faz-se necessário, além da utilização de genótipos mais produtivos, o oferecimento de um ambiente compatível com o requerimento do animal (Façanha et al., 2013). Apesar de ambas as cidades pertencerem à região semiárida brasileira, a cidade de São Bento do Una se encontra na mesorregião Agreste Meridional e apresenta condições climáticas mais amenas quando comparada à cidade de Arcoverde, situada na mesorregião do Sertão do Moxotó. Segundo Azevedo et al. (2005), a zona de termoneutralidade para bovinos leiteiros situa-se entre $5^{\circ} \mathrm{C}$ e $25^{\circ} \mathrm{C}$; com isso, torna-se evidente o nível de estresse ao qual o rebanho Girolando foi submetido, visto que temperaturas superiores ao nível crítico indicado na literatura foram observadas em vários meses dos anos analisados, além dos elevados valores de umidade relativa do ar e ínfimas médias de precipitação (Fig. 3). 
Os resultados da análise de variância demonstraram que o efeito dos polimorfismos foi mais significativo na raça Holandesa $(\mathrm{P}<0,0001)$, apesar de este também influenciar os níveis produtivos dos animais Girolando $(\mathrm{P}<0,0117)$, o que provavelmente ocorre em razão da origem genética das raças. Os bovinos taurinos evoluíram em clima temperado e não foram expostos aos desafios presentes nas regiões tropicais, enquanto os zebuínos evoluíram nos trópicos, na presença de elevadas cargas de calor, resultando em raças que possuem boa adaptação ao estresse térmico (Jorge, 2013).

Tabela 4. Efeitos dos polimorfismos (A, B, C... G do gene HSP-70.1 sobre a produção de leite (L/dia) dos rebanhos das raças Holandesa e Girolando

\begin{tabular}{ccccc}
\hline \multirow{2}{*}{ F.V. } & \multicolumn{2}{c}{ Holandesa } & \multicolumn{2}{c}{ Girolando } \\
\cline { 2 - 5 } & F calculado & $\mathrm{P}>\mathrm{F}$ & F calculado & $\mathrm{P}>\mathrm{F}$ \\
\hline Padrão & 12,59 & $<0,0001$ & 3,24 & 0,0117 \\
Ano & 17,10 & $<0,0001$ & 39,60 & $<0,0001$ \\
Mês & 7,77 & $<0,0001$ & 0,65 & 0,7910 \\
Ano*Mês & 4,40 & $<0,0001$ & 2,10 & $<0,0001$ \\
Precipitação $(\mathrm{mm})$ & 0,17 & 0,6762 & 0,01 & 0,9162 \\
Temperatura $\left({ }^{\circ} \mathrm{C}\right)$ & 0,74 & 0,3914 & 2,89 & 0,0891 \\
Umidade relativa $(\%)$ & 1,29 & 0,2555 & 2,03 & 0,1541 \\
\hline
\end{tabular}

F.V.: fontes de variação.

As variáveis climáticas não apresentaram influência para os rebanhos, provavelmente porque esses animais há algumas décadas, foram submetidos a processo de seleção. Os efeitos dos fatores ano, mês e a interação ano x mês foram significativos para ambos os rebanhos. Apesar de as condições climáticas divergirem entre as mesorregiões do estado, quando ocorrem longos períodos de estiagens, seus efeitos causam transtornos para toda a região e desencadeiam consequências severas que influenciam diretamente no manejo alimentar adotado nas propriedades, sendo a acentuada redução na oferta e qualidade da forragem durante as estações secas o fator determinante para redução dos níveis produtivos (Silva et al., 2010).

Diferenças significativas para a variável produção de leite foram observadas em razão dos padrões alélicos obtidos, para ambos os rebanhos (Tab. 5). Nos animais provenientes de São Bento do Una, os padrões A e $\mathrm{C}$ apresentaram médias superiores e mostraram-se estatisticamente diferentes dos demais padrões observados nesse rebanho. Em contrapartida, nos animais Girolando foram os padrões E e D que se destacaram, apesar de estes não apresentarem diferenças significativas em relação aos padrões F e G. As médias de produção para os polimorfismos do gene HSP70.1 apresentaram-se mais uniformes na raça Girolando; provavelmente o manejo conduzido nesse rebanho, que não apresenta nenhum artificio para redução do estresse térmico dos animais, possa ter colaborado para os resultados apresentados.

Tabela 5. Médias da produção de leite (L/dia) para cada padrão alélico do gene HSP-70.1 nas raças Holandesa e Girolando criadas no estado de Pernambuco

\begin{tabular}{ccc}
\hline Padrão & Holandesa & Girolando \\
\hline A & $24,35^{\mathrm{a}}$ & \\
B & $17,64^{\mathrm{b}}$ & $8,50^{\mathrm{b}}$ \\
C & $23,06^{\mathrm{a}}$ & \\
D & $18,74^{\mathrm{b}}$ & $9,31^{\mathrm{a}}$ \\
E & $17,22^{\mathrm{b}}$ & $9,40^{\mathrm{a}}$ \\
F & & $9,15^{\mathrm{ab}}$ \\
G & & $8,65^{\mathrm{ab}}$ \\
\hline
\end{tabular}

*Médias seguidas pela mesma letra não diferem entre si pelo teste $\mathrm{t}(\mathrm{LSD})$ a $5 \%$ de probabilidade.

\section{CONCLUSÕES}

Existe associação entre polimorfismos do gene HSP-70.1 com a produção de leite de bovinos leiteiros criados na região semiárida do estado de Pernambuco. Os rebanhos avaliados apresentaram padrões de polimorfismos diferentes, os quais podem ser utilizados como indicadores de termotolerância desde que sejam levadas em consideração as diferenças raciais assim como as condições climáticas apresentadas na região onde os animais estejam localizados. O conhecimento da variabilidade genética do gene HSP-70.1 vem a contribuir grandemente para a bovinocultura de leite da região de abrangência do trabalho, 
possibilitando a exploração das diferentes respostas apresentadas sob condições de estresse térmico por calor.

\section{REFERÊNCIAS}

ADAMOWICZ, T.; PERS, E.; LECHNIAK, D. A new SNP in the 3'-UTR of the HSP-70.1-1 Gene in Bos taurus and Bos indicus. Biochem. Genet., v.43, p.623$627,2005$.

AZEVEDO, M.; PIRES, M.F.; SATURNINO, H.M. et $a l$. Estimativa de níveis críticos superiores do índice de temperatura e umidade para vacas leiteiras 1/2, 3/4 e 7/8 Holandês-Zebu em lactação. Rev. Bras. Zootec., v.34, p.2000-2008, 2005.

BERMAN, A. Invited review: are adaptations present to support dairy cattle productivity in warm climates? J. Dairy Sci., v.94, p.2147-2158, 2011.

BERNABUCCI, U.; LACETERA, N.; BAUMGARD, L.H. et al. Metabolic and hormonal acclimation to heat stress in domestic ruminants. Animal, v.4, p.1167-1183, 2010.

BRADLEY, D.G.; MACHUNG, D.E.; CUNNINGHAM, P. et al. Mitochondrial diversity and the origins of African and European cattle. Proc. Natl. Acad. Sci., v.93, p.5131-5135, 1996.

CAMARGO, L.S.; VIANA, J.H.; RAMOS, A.A. et al. Developmental competence and expression of the Hsp 70.1 gene in oocytes obtained from Bos indicus and Bos taurus dairy cows in a tropical environment. Theriogenology, v.68, p.626-632, 2007.

CASTRO, S.V.; LOBO, C.H.; FIGUEIREDO, J.R. et al. Proteínas de choque térmico Hsp70: estrutura e atuação em resposta ao estresse cellular. Acta Vet. Bras., v.7, p.261-271, 2013.

DELFINO, L.J.B.; SOUZA, B.B.; SILVA, R.M.N. et al. Influência de diferentes ambientes de pré-ordenha sobre os valores hematológicos de vacas Pardo-suíças em sistema biodinâmico de produção. Agropec. Cient. Semi Árido, v.8, p.8-15, 2012.

EXCOFFIER, L.; LISCHER, H. Arlequin suíte ver 3.5: Uma nova série de programas para realizar análises de genética de populações sob Linux e Windows. Mol. Ecol. Resour., v.10, p.564-567, 2010.

FAÇANHA, D.A.; CHAVES, D.F.; MORAIS, J.H. et al. Tendências metodológicas para avalilação da adaptabilidade ao ambiente tropical. Rev. Bras. Saúde Prod. Anim., v.14, p.91-103, 2013.
GADE, N.; MAHAPATRA, R.K.; SONAWANE, A. et al. Molecular characterization of heat shock protein 701 Gene of goat (Capra hircus ). Mol. Biol. Int., v 47, p.111-116, 2010.

GROSZ, M.D.; WOMACK, J.E.; SKOW, L.C. Syntenic conservation of HSP-70.1 genes in cattle and humans. Genomics, v.14, p.863-868, 1992.

HANSEN, P.J. Physiological and cellular adaptations of zebu cattle to thermal stress. Anim. Reprod. Sci., v.82, p.349-360, 2004.

JACCARD, P. Nouvelles recherches sur la ditribuition florale. Bull. Soc. Vaudoise Sci. Nat., v.44, p.223-270, 1908.

JORGE, W. A genômica bovina - origem e evolução de taurinos e zebuinos. Vet. Zootec., v.20, p.217-237, 2013.

LIMA, R.S.; ASSUMPÇÃO, M.E.; VISITIN, J.A.; LOPES, F. et al. Alterações celulares induzidas pelo estresse térmico em embriões bovinos. Braz. J. Vet. Res. Anim. Sci., v.50, p.257-264, 2013.

MANJARI, R.; YADAV, M.; RAMESH, K. et al. HSP70 as a marker of heat and humidity stress in Tarai buffalo. Trop. Anim. Health Prod., v.47, p.1-7, 2015.

MARÓTI-AGÓTS, Á.; BODÓ, I.; JÁVORKA, L. et al. Possible genetic sign of heat stress adaptation in Hungarian Grey Bos taurus breed. Acta Biol. Hung., v.62, p.65-72. 2011.

NUNES, M.; YERLE, M.; DEZEURE, F. et al. Isolation of four HSP-70.1 genes in the pig and localization on Chromosomes 7 and 14. Mamm. Genome, v.4, p.247-251, 1993.

SCHWERIN, M.; SANFTLEBEN, H.; GRUPE, S. Genetic predisposition for productive life isassociated with functional inactivation of a AP2-binding site in the promoter of thestress protein 70.1-encoding gene in cattle. Arch. Tierz. Dummerstorf, v.46), p.177-185, 2003.

SILVA, T.G.; MOURA, M.; SÁ, I.S. et al. Cenários de mudanças climáticas e seus impactos na produção leiteira em estados nordestinos. Rev. Bras. Eng. Agríc. Ambiental, v.14, p.863-870, 2010.

WOLFENSON, D.; ROTH, D.; MEIDAN, R. Impaired reproduction in heat-stressed cattle: basic and applied aspects. Anim. Reprod. Sci., v.60, p.535-547, 2000.

ZANELA, M.B.; FISHER, V.; RIBEIRO, M.E. et al. Qualidade do leite em sistemas de produção na região Sul do Rio Grande do Sul. Pesqui. Agropecu. Bras., v.41, p.153-159, 2006. 